\title{
A DIFERENÇA DO USO E NÃO USO DO LIVRO DIDÁTICO EM DUAS ESCOLAS NAS AULAS DE LÍNGUA INGLESA
}

The difference between the use and non-use of the textbook in two schools in English language classes La diferencia entre usar y no usar el libro de texto en dos escuelas en clases de inglés Miliane M. C Vieira ${ }^{1}$, Kaliny Alves Miranda Reis ${ }^{2}$, Osmar de Melo Lima Neto $^{3}$, Davi Pereira Gomes ${ }^{4}$, Sharon Elaine da S. G. Toledo ${ }^{5}$

Artigo Original Original Article Artículo Original

\footnotetext{
${ }^{1}$ Docente do Curso de Graduação em Letras - Língua Inglesa e Literaturas, Universidade Federal do Tocantins UFT, Araguaína, Tocantins, Brasil.

${ }^{2}$ Acadêmica, Letras-Língua Inglesa e Literaturas, UFT- Universidade Federal do Tocantins, Araguaína-Campus Cimba, Brasil.

${ }^{3}$ Acadêmico, Letras-Língua Inglesa e Literaturas, UFT- Universidade Federal do Tocantins, Araguaína-Campus Cimba, Brasil.

${ }^{4}$ Professor da Educação Básica, Secretaria de Estado da Educação, Juventude e Esportes do Tocantins - SEDUC, Araguaína, Tocantins, Brasil

${ }^{5}$ Professora da Educação Básica, Secretaria de Estado da Educação, Juventude e Esportes do Tocantins - SEDUC, Araguaína, Tocantins, Brasil.
}

*Correspondência: Laboratório de Ciências, Instituto de Ensino Superior, Av. NS 15, 109 Norte, Palmas, Tocantins, Brasil.CEP:77.010-090.e-mailartigo@artigo.com.

\section{INTRODUÇÃO}

Este artigo busca comparar duas escolas de Araguaína (TO) na questão do uso e não uso do livro didático de Língua Inglesa. Ao longo deste artigo explicaremos o porquê uma escola optou pela utilização do material e a outra instituição não. Enquanto cursávamos o curso de Letras - Língua Inglesa e Literaturas da Universidade Federal do Tocantins, participamos do Programa de Residência Pedagógica (PRP). Através desse programa, nossas experiências teórico-práticas foram realizadas em duas escolas: uma no ensino fundamental e outra no ensino médio.

O presente artigo trata de reflexões, nas quais destacamos obstáculos e desafios enfrentados nas duas escolas públicas de Araguaína (TO). No entanto, sabemos que as línguas estrangeiras assumem condições importantes no currículo escolar, assim como as outras disciplinas, pois

[...] Integradas a área de linguagens, Códigos e suas Tecnologias, as Línguas Estrangeiras assumem a condição de serem indissolúvel do conjunto de conhecimentos essenciais que permitem ao estudante aproximar-se de várias culturas [...]. (BRASIL, 2000, p, 25)

Dada essa importância, as línguas estrangeiras, como parte indissolúvel do conjunto de conhecimentos, podem proporcionar aos alunos acesso ao conhecimento de diferentes culturas e a uma nova maneira de pensar e agir. Assim, como embasamento teórico utilizamos documentos que trazem orientações sobre o ensino de Língua Inglesa no contexto brasileiro: OCEM (Orientações Curriculares para o Ensino Médio), PCN 
(Parâmetros Curriculares Nacionais), Orientações

Educacionais Complementares Aos Parâmetros

Curriculares Nacionais ( $\mathrm{PCN}+$ Ensino Médio) e

Parâmetros curriculares nacionais terceiro e quarto ciclos do ensino fundamental: Língua Estrangeira.

\section{METODOLOGIAS E MATERIAIS}

Essa pesquisa foi realizada em duas escolas em Araguaína (TO). Nomearemos de escola (A) a instituição de ensino fundamental e de escola (B) a instituição de ensino médio. Em ambas foram lecionadas aulas de Língua Inglesa (LI), mas na escola (A) houve o uso do livro didático; e na escola (B) não.

$\mathrm{Na}$ escola (A) como mencionamos, utilizamos o livro didático adaptado para a realidade dos estudantes, e desenvolvemos o conteúdo programático da escola campo. Com o intuito de evitar que nas aulas de Língua Inglesa os alunos ficassem dispersos, em nossas aulas aplicamos atividades interativas e dinâmicas para complementar o uso do livro didático.

$\mathrm{Na}$ escola (B) trabalhamos com o ensino médio. E como dito anteriormente, não tínhamos acesso ao livro didático nesta escola. A priori pensamos que o não uso do livro didático dificultaria o nosso trabalho. Mas, seguimos os conteúdos programáticos da escola e desenvolvemos mais atividades lúdicas tendo como base conteúdos extraídos da internet.

Durante o período do Programa Residência Pedagógica sentimos uma diferença entre uma escola e outra, tanto na estrutura quanto na equipe. A escola (A), localizada em um bairro periférico de Araguaína (TO), é uma escola pequena, de estrutura simples, porém os funcionários são muito receptivos e acolhedores. O diretor, os dois coordenadores, professores e demais funcionários mantinham bom relacionamento profissional, assim a equipe estava sempre em harmonia. A instituição disponibilizou a cada residente um livro didático das séries que lecionaríamos.

A escola (B), localizada em um bairro próximo ao Centro de Araguaína (TO), é uma escola maior, com uma boa equipe. No entanto, nessa escola não foi possível obter o livro didático, uma vez que esse material foi recolhido pela escola. A justificativa de recolher o livro didático foi de não ser utilizado pelos próprios professores da escola, ou seja, o uso do material não é uma prática comum nas aulas de LI. Quando pedíamos a professora o livro, a mesma nos dizia para fazermos cópias das páginas que íamos usar em cada aula.

Não acreditamos que a sugestão da professora fosse uma proposta viável, porque toda vez que precisássemos utilizar o livro em nossas aulas teríamos que fazer cópias e a escola não tinha papel A4 suficiente. Assim, não podíamos recorrer rapidamente ao livro didático e fazer cópias sem papel A4, mesmo que quiséssemos utilizar o livro de maneira não linear, ou seja, sequencialmente.

Ademais, com as novas formas de leitura não linear, pode-se pensar em livros didáticos que estão cada vez mais, chegando com novos recursos e, consequentemente, novas formas de leitura. Segundo Ludwig e Machado (2017), o livro deve seguir os avanços tecnológicos e as demandas socioculturais no mundo globalizado. Assim, os livros didáticos podem ser usados nas aulas de Língua inglesa de maneira não linear, explorando os novos recursos tecnológicos que ele possui.

\section{RESULTADOS E DISCUSSÃO}

Hoje, depois de terminarmos a terceira fase da residência pedagógica, podemos olhar para trás e lembrarmos-nos do nosso primeiro contato com as escolas, na fase de observação. Podemos notar o quanto aprendemos e os medos de não 
conseguirmos foram superados. Tivemos um ganho enorme em experiências, pois passamos muito mais tempo na escola campo: com os professores, demais funcionários da escola, alunos e ministramos mais aulas tanto no ensino fundamental quanto no ensino médio.

Nas regências da escola (A), de ensino fundamental, tínhamos a impressão de que as aulas de 50 minutos, o tempo passava mais rápido. Desta forma, os alunos geralmente não conseguiam concluir as atividades que tínhamos preparado para as aulas, pois os alunos desenvolvem as atividades em um ritmo mais lento. Principalmente se forem atividades escrita no quadro, eles demoravam muito tempo para terminar. Já no ensino médio, escola (B), tivemos que pensar e elaborar planos de aula com mais conteúdos para cada aula. Como os adolescentes são capazes de desenvolver as atividades propostas, em um ritmo mais rápido, nós podíamos exigir mais deles nas aulas de LI.

Na escola (B), devido à mudança no horário escolar, tivemos a oportunidade de ministrar aulas na primeira, segunda e terceira séries. Podemos lembrar que no início da terceira fase da RP, nos sentimos um pouco inseguros quando recebemos a notícia da professora preceptora que iriamos ministrar aulas na terceira série. Mas, depois de lecionarmos na primeira, segunda e terceira séries percebemos que trabalhar com a terceira série não seria ruim, porque eles eram mais participativos.

$\mathrm{Na}$ primeira e segunda séries havia mais alunos desmotivados e dispersos nas aulas de LI. Para motivá-los, decidimos planejar aulas mais lúdicas por meio de dinâmicas. Montamos um jogo de tabuleiro (Game Board), realizamos Bingo entre outras atividades lúdicas para trabalharmos os conteúdos programáticos da escola. Mesmo adaptando os conteúdos com as dinâmicas, para que as aulas de LI DOI: http://dx.doi.org/10.20873/uftsupl2020-8810 se tornassem mais atrativas, ainda assim sentíamos falta do livro didático.

Acreditamos que o uso do livro seja importante nas aulas de LI, pois pode ajudar o professor e facilitar o aprendizado dos alunos. O livro didático pode contribuir significativamente para aproximar os estudantes de várias culturas e promover pensamento crítico. Outro fator importante é saber utilizá-lo de modo que não seja como a única ferramenta, e sim como um complemento para as aulas de LI. Assim, é necessário que o professor saiba adaptar aos conteúdos programáticos ao contexto (realidade) de vida dos alunos de forma não linear.

Nas aulas da primeira e segunda séries do ensino médio trabalhamos mais com a leitura e interpretação de textos, seguindo as orientações de que:

A competência primordial do ensino de línguas estrangeiras modernas no ensino médio deve ser a da leitura e por decorrência, a da interpretação. $\mathrm{O}$ substrato sobre o qual se apoia a aquisição dessas competências constitui-se no domínio de skimming, scanning, prediction, bem como na percepção e na identificação de índices de interpretação textual [...] (BRASIL, 2002, p.97)

De acordo com o PCN+ Ensino médio (2002), é muito importante trabalhar com a leitura no ensino médio, para promover/estimular a capacidade de interpretação do aluno. E as aulas de leitura podem ser trabalhadas com técnicas de leitura como skimming, scanning e prediction para textos em língua estrangeira.

A estratégia de leitura "skimming" serve para dar ao leitor uma compreensão geral do assunto abordado pelo texto, em uma olhada rápida e superficial, procurando explorar as informações do texto. "Scanning" é uma busca por informações objetivas, uma leitura mais específica quando se deseja encontrar um significado particular, informação específica no texto. E "prediction" é uma atividade de pré-leitura na qual o leitor é Revista Desafios - v. 7, n. Supl. RP-UFT, 2020 
levado a deduzir o conteúdo do texto, conhecimento prévio da leitura.

Em uma das aulas que trabalhamos leitura na turma de primeira série, levamos um pequeno texto intitulado "My city", com esse título a maioria dos alunos sabiam sobre o que era o texto, o que podemos chamar de "prediction" no primeiro momento. Depois da leitura do texto descritivo, os alunos começaram a identificar algumas palavras e fizeram uma compreensão geral. Ao terminarem a leitura, estava na hora de fazermos algumas perguntas sobre o que foi lido. Com as questões, os estudantes retomaram suas leituras em busca de informações específicas para responder ao pequeno questionário.

$\mathrm{Na}$ escola (A), tivemos a oportunidade de usar o livro como complemento em nossas aulas e percebemos que as aulas tinham melhores resultados. O uso desse material didático é cobrado nas aulas de LI como um recurso a mais, então os alunos já sabiam que os professores usam o livro em sala. Desta forma, os estudantes sempre traziam os livros para as aulas, apesar de que um ou outro esquecia de vez em quando.

Embora não tenhamos usado o livro didático na escola (B), porque o uso do material não é uma prática comum na instituição, percebemos que havia a necessidade de usar o livro didático como um complemento para enriquecer nossas aulas de inglês. Segundo a escola, um dos motivos para o não uso do livro didático é que os alunos não traziam os livros para as aulas de LI, e o material didático não era cobrado pelos professores de LI. Assim, os estudantes entendiam que o livro didático não era necessário para as aulas de língua inglesa, por isso foi recolhido. Então, a Internet era o único recurso para elaborarmos os conteúdos que seriam expostos em aula.
No início do trabalho com o livro didático, encontramos dificuldades, porque havia discordância entre o conteúdo programático da escola e o livro. A maioria dos conteúdos programáticos da escola não coincidia nos conteúdos do livro didático. O que nos ajudou foram as orientações recebidas ao longo da RP pela professora orientadora. Assim, aprendemos que não é necessário acompanhar as atividades ou o conteúdo do livro de maneira linear; pode-se escolher como trabalhar, adaptando o conteúdo programático e escolhendo o capítulo do livro que mais se adequava com o assunto que seria abordado nas aulas.

\section{CONCLUSÃO}

Como sabemos a região tocantinense não tem a prática de valorizar o ensino/aprendizado da língua inglesa. Sentíamos uma resistência por parte dos alunos do ensino fundamental. Eles diziam as expressões "não sei por que estudar essa disciplina", "nem vou sair do Brasil". Essas são expressões desmotivadoras que acabam circulando, mas o professor pode tentar mudar isso com aulas, discursos motivacionais, não apenas para os alunos, mas para todo o ambiente escolar.

(...) O aprendizado de uma língua estrangeira, juntamente com a língua materna, é um direito de todo cidadão, conforme expresso na lei de Diretrizes e Bases e na Declaração Universal dos Direitos Linguísticos, publicada pelo Centro Internacional de Minorias e Nações Étnicas (CIEMEN) e pelo PEN-International Club. Portanto, a escola não pode mais se omitir em relação a esse aprendizado. (BRASIL, 1998, p.19)

Ao estar ciente de que aprender uma língua estrangeira é um direito de todo cidadão e que existe uma lei que garante esse direito, as escolas não podem omitir-se em relação a esse aprendizado. Infelizmente, o ensino de língua estrangeira nas escolas não é visto com a devida importância, como uma disciplina que oferece inúmeros benefícios para a formação dos alunos. Pelo contrário, é vista como Revista Desafios - v. 7, n. Supl. RP-UFT, 2020 
uma disciplina para preencher lacunas, em geral por funcionários e alunos da escola. No entanto, o que os alunos e funcionários da escola não sabem é que aprender uma língua estrangeira junto com a língua materna é um direito garantido por lei.

Ao final dessa experiência no Programa Residência Pedagógica, tivemos a oportunidade de vivenciar a prática em duas escolas com realidades diferentes, nas quais adquirimos um grande aprendizado. Com os erros, sabemos o que precisamos melhorar e com os acertos, sabemos que o ensino esta sendo efetivo, contudo é sempre bom estar disposto a inovar.

\section{AGRADECIMENTO}

Agradecemos ao Programa Residência Pedagógica (PRP), no Subprojeto de Letras - Língua Inglesa, promovido pela Coordenação de Aperfeiçoamento de Pessoal de Nível Superior Capes, conforme o Edital CAPES n ${ }^{\circ} 06 / 2018$, com a participação da Universidade Federal do Tocantins (UFT) e da Secretaria de Estado da Educação, Juventude e Esportes do Tocantins (SEDUC). E, também, a cada um dos colaboradores deste trabalho: Orientadora da Residência Pedagógica de Língua Inglesa, o preceptor da escola A, a Preceptora da escola B e os alunos tanto do ensino fundamental quanto do ensino médio.

Todos os autores declararam não haver qualquer potencial conflito de interesses referente a este artigo.

\section{REFERÊNCIAS}

BRASIL. Orientações Curriculares Para O Ensino Médio: Linguagens, Códigos e suas Tecnologias. Brasília: MEC/SEB, 2006.

BRASIL. Orientações Educacionais Complementares Aos Parâmetros Curriculares Nacionais (PCN+ Ensino Médio). Linguagens, Códigos e suas Tecnologias. Brasília: MEC, 2002.

BRASIL. Parâmetros Curriculares Nacionais (Ensino Médio): Linguagens, códigos e suas Tecnologias. Brasília: MEC, 2000.

BRASIL. Secretaria de Educação Fundamental. Parâmetros curriculares nacionais terceiro e quarto ciclos do ensino fundamental: Língua Estrangeira/ Secretaria de Educação Fundamental. Brasília: MEC/SEF, 1998.

LUDWIG, Carlos Roberto; MACHADO, Luzia Angélica Moreira. O mundo plástico dos materiais didáticos: uma análise do livro Interchange numa perspectiva intercultural. Entreletras. Araguaína/TO, v. 8 , n. 2 , jul./dez. 2017. 